\title{
INDRUM2016 Special Issue Editorial
}

\author{
Elena Nardi $^{1} \cdot$ Carl Winsløw $^{2}$ (D)
}

Published online: 7 March 2018

(C) Springer International Publishing AG, part of Springer Nature 2018

\section{Background: The Birth of INDRUM}

University Mathematics Education (UME) is a field of practice that is currently challenged at a number of levels: in many countries, there are manifest recruitment and retention problems for study programmes in pure and applied mathematics, as well as in other study programmes that include a substantial mathematics component. University mathematics teachers increasingly experience that students have highly variable mathematical preparation from secondary school, and find that they themselves need new tools and perspectives for dealing with the changing student populations that they work with. Mathematics courses, not least at the entry level, are often found to have alarming failure rates, or other difficulties in achieving the learning goals specified by the syllabus, and required in later courses. Most institutions have established support measures for students, such as "remedial courses", mathematics learning support services, and so on; they are both a symptom of the challenges outlined above, and attempts to address them. These challenges seem to explain, at least partly, the growing demand for research and development initiatives related to UME.

In fact, the challenges which students face in mathematics courses may, at first sight, be seen as calling for local development, that is, initiatives to improve the practice and organisation within a single institution (such as a university, study programme or course). However, the similarity of problems identified across institutions, as well as the need to base development initiatives on solid and explicit grounds, also implies a need for research - that is, establishing knowledge on which development can be grounded, and which is meaningful and valid across institutions and is warranted by theoretically informed and empirically based investigations. The fact that research

Elena Nardi

E.Nardi@uea.ac.uk

Carl Winsløw

Winslow@ind.ku.dk

1 University of East Anglia, Norwich, UK

2 University of Copenhagen, Copenhagen, Denmark 
problems and results can be shared across institutions, assuming explicit consideration of context, also means that research on UME becomes increasingly international, as it expands in scope, sophistication and volume.

One clear sign of this development is the creation and growth of the thematic working group on University Mathematics Education at the ERME (European Research in Mathematics Education) Congress, CERME. This group has grown considerably since its launch in 2011, to become the largest in the latest CERME held in Dublin in 2017 (Winsløw et al. 2018). The creation of INDRUM (International Network for Didactic Research on University Mathematics) in 2015, during CERME9 in Prague, was one fruit of the collaboration within the group. This initiative can also be seen as one example of a tendency towards synthesis emerging from research collectives that have formed at several conferences across the world (Nardi 2017).

\section{The INDRUM Conferences}

INDRUM2016 (Montpellier, March 31 - April 2, 2016) was the first in what is planned as a series of biennial conferences that address all aspects of research in didactics of mathematics at tertiary level, on two broad themes: students' and teachers' practices and the teaching and learning of specific mathematical topics. We were delighted to receive 81 submissions ( 63 full papers, 18 poster proposals) with 46 full papers and 15 posters eventually comprising the conference programme and the subsequent proceedings volume. A plenary by Michèle Artigue focused on the achievements and challenges of UME research in the last 20 years and a panel discussion led by Marianna Bosch explored the theme of interactions between mathematicians and researchers in mathematics education. The conference attracted 100 registered participants and the invitation to submit a paper for the present special issue was addressed to all soon after the conference closing. Based on the papers received, five thematic groups were formed to structure the conference programme: Calculus and analysis; Modelling and mathematics in other disciplines; Logic, numbers and algebra; Teachers' practices and institutions; and Students' practices. The conference was organised in the CERME spirit, with the five thematic working groups organising the presentation and discussion of the papers allocated to each. There are papers in the present special issue that reflect the discussions in each of the five working groups.

\section{The Story of this Special Issue}

We are delighted to present this Special Issue in the International Journal for Research in Undergraduate Mathematics (IJRUME). As INDRUM2016 Chairs, we guest-edited this Special Issue with support from the IJRUME Editors and from reviewers who were members of the INDRUM2016 Scientific Committee and/or the IJRUME Editorial Board.

We invited papers of 6000-8000 words in length, written in English, and with the abstract in both English and French, to reflect that INDRUM2016 had these two working languages. We received 23 submissions and ten of these made it to this Special Issue. We aimed for the Special Issue to be ready in time to celebrate its publication at INDRUM2018 in Kristiansand, Norway - and we are very pleased that it is! 
This Special Issue reflects the thematic range and richness of the INDRUM2016 programme. Its overall aim is to publish some of the best research presented at INDRUM2016. Bearing in mind that conference papers often outline a small part of a larger study, we particularly welcomed papers that elaborate and expand substantially what was presented at the conference and published in the Proceedings (Nardi et al. 2016). We see the ten papers in this Special Issue doing so in the following way: all papers are based on one or more papers presented in the conference, and they certainly draw on some of the work accomplished within each of the five thematic groups. Needless to say, the procedures and quality standards of the journal were meticulously observed. It is also obvious that the ten papers which comprise this special issue do not represent the entire breadth of work presented at the conference. Nonetheless, these ten papers cover a broad range of theoretical perspectives, mathematical and pedagogical foci as well as methodologies deployed within the INDRUM community. We notice that more than half of the papers draw on the Anthropological Theory of the Didactic (ATD: Chevallard 2018; Winsløw 2015), a framework that is extensively present also in several, recent CERME UME papers. We believe that the issue presents a valid and original selection of state-ofthe-art research works that report not only accomplished results but also suggest important perspectives for future pursuits in our field. We now outline each one of the ten contributions to highlight how each does both.

\section{What the Papers in this Special Issue Have to Offer}

Barquero, Monrela, Ruiz-Monzón and Serrano designed and trialled an experimental study and research path (in the sense of ATD) with first year business students. Students engaged with the generating question: How will the global number of Facebook users develop? Students examine this question based on data, prerequisite knowledge, and course material (not least from basic statistics). The paper focuses on the dynamics between, on one hand, the students" "research" based on prerequisite knowledge, and on the other hand, the study of new knowledge (to them), in the setting of more commonplace transmissive teaching. The experiment gives rise to further hypotheses related to the potential of study and research paths at university level, in particular for having the teaching of mathematics and statistics interact more directly with other disciplines in the students' programme, and for combining modeling and inquiry with units of "normal" content-driven teaching.

Bosch, Gascón and Nicolás present a theoretical analysis of two different approaches to inquiry based teaching of group theory, both situated within the framework of ATD. The first analysis concerns task design based on a praxeological analysis of the basic definitions and results in group theory, with the aim of providing students with a broader and more autonomous practical experience related to the theoretical elements. This first analysis is contrasted with a deeper inquiry (by students) into the raison d'etre of group theory. As an example, Bosch et al. outline a study and research path on the symmetries of a square as a possible direction in which this subject can be developed more naturally from students' previous knowledge of mathematics. The main points of the paper are (1) to address a broader problem facing undergraduate courses in pure mathematics, namely that subjects such as group theory tend to appear and pass at a 
high pace, with little visible motivation and rationale for students; and, (2) to propose the "paradigm of questioning the world" as a strategy to address it.

Broley explores the place of computer programming in the research and teaching practices of university mathematicians. She builds on prior research that identified differences between research and teaching practices, and aims to capture the differences through drawing on praxeological (ATD) analysis, as well as Morrissette's (2011) triad of shared, admitted and contested practices. She identifies six levels at which the professional mathematicians might interact with programming. Her analysis allows her to note important differences between the praxeologies of individual mathematicians and those they propose to their students, with the latter rarely involving the most active version of the highest level. She also notes that while programming at the highest level is shared or admitted within applied or pure mathematics research communities, respectively, it may still be rejected or contested within institutions where mathematics is taught and learnt. Reasons why this gap may occur include variability of institutional constraints (curricular, departmental and cultural). There was uniform support for the potential benefits (epistemic, pragmatic and sociocultural) of reducing the gap and her findings acknowledge that a nuanced, far from hierarchical interpretation of the six levels is needed when deciding which levels of programming students may be exposed to in various tasks.

Gueudet and Pepin study teaching and learning issues that characterise the beginning of university mathematics studies by introducing a link between the Theory of Didactical Situations (Brousseau 1997) and the Documentational Approach (Gueudet and Trouche 2009) - and deploying this link to investigate the university mathematics didactic contract at three levels (institutional, mathematical domain, specific mathematical topic), especially in relation to how students use resources. The analyses presented in the paper originate in two complementary case studies, one in the UK and one in France, and focus on identifying didactic contract rules at the three levels, both for students and for teachers. The analysis identifies discrepancies between students' and teachers' rules, and also between those two sets of rules and the explicit rules of the institution. Gueudet and Pepin note that these discrepancies may impede students' effective engagement with university mathematics and they highlight ways in which that these gaps can be reduced. They propose that university mathematics teachers can make expectations from students about how to use resources more explicit and that the university institution can also improve the alignment between resources offered to students and students' approaches to study.

Hausberger outlines and exemplifies a new research programme on the teaching and learning of abstract algebra, based on careful analysis of what he calls structuralist praxeologies. These are characterised by a dialectics between the particular and the general, corresponding to three levels of abstraction at which a given task may be approached; and by a dialectics of objects and structures, as seen in quotient constructions based on morphisms (such as the passage from integers to rational numbers). As an example to illustrate the use of this epistemological model to analyse the achievements and shortcomings of students' autonomous development of structuralist praxeologies, Hausberger analyses a very rich thread from an Internet forum, where a group of (presumably) students discuss the task of deciding whether a given ring (in casu, the ring of finite decimals) is a principal ideal domain. The paper concludes with discussing designs of formal teaching in view of achieving similar dynamics. 
Kidron sets out from the observation that constructing the field of real numbers is a key part of students' introduction to university mathematics and that therefore the study of their pre-university conceptions of irrational numbers is important. Drawing on Fischbein's (1987) classic works on infinity, she examines upper secondary students' conceptions of irrational numbers and she finds that, even though most students claimed that they had learned about irrational numbers, only a fifth demonstrated awareness of the irrational numbers as non-repeating infinite decimals or of their presence on the real number line. She also observes that many of those who showed awareness of irrational numbers as non-repeating infinite decimals also wrote in their responses that only rational numbers appear on the number line. She concludes that instruction that places emphasis on both representations is needed.

Kondratieva and Winsløw set out from what Verret (1975) called the desynchretisation of knowledge: the separation, for the purpose of teaching, of elements of knowledge which were originally combined and united - and examine the implications that this desynchretisation has on undergraduate mathematics. The paper proposes reviving Klein's (1908/2016) idea of "Plan B" in order to provide early resynchretization experiences and does so through praxeological (ATD) analyses in two cases that re-link the theory of analysis with practical knowledge from calculus: in the first, Kondratieva and Winsløw consider the contribution of vector analysis to the foundations of trigonometric functions, and in the second case they establish links between the proof of a basic theorem in Fourier Analysis and the computation of elementary infinite series. Through small-scale trials of their propositions, Kondratieva and Winsløw pave the way for what they describe as a much needed, important and feasible new didactical research agenda which aims to help students integrate mathematical theories and practices that are otherwise taught separately.

Montoya Delgadillo, Murillo, Vandebrouck and Vivier draw on Vandebrouck's (2011) theoretical construct of three localization perspectives (pointwise, local and global), initially proposed for the topic of functions, and expand it towards the study of more objects in real analysis. The paper presents two cases: computing the tangent to a curve and computing the limit of a function. Montoya Delgadillo et al. see the importance of localization perspectives for mathematical work in their capacity to extend classical binaries in mathematics education such as potential/actual and local/ global. The paper draws on earlier analyses of data with first-semester university students studying science and presents the argument in favour of using localization perspectives towards understanding students' mathematical work in terms of deconstructions with localization perspectives, good coordination between localization perspectives, and the benefits thereof.

Thoma and Nardi analyse four types of commognitive conflict (Sfard 2008) which can be observed in students' examination scripts from a first year module, particularly in the light of the lecturer's assessment comments. The conflicts observed concern the discursive context intended by the lecturer (but not assumed by the students), the use of visual mediators in different domains of mathematics (in casu, probability theory, set theory and school algebra), and the often different discursive rules that govern these domains. The paper makes the case that unresolved commognitive conflicts of these four types are central components of the students' experience of the transition from school to university mathematics, as well as of their difficulties with distinguishing and mastering the discourses expected in different domains of university mathematics. 
While it is understandable that discursive rules and norms tend, in general, to be implicit, meta-level knowledge of the aforementioned types of conflict may assist lecturers to address these difficulties more effectively.

Trigueros Gaisman, Martínez-Planell and McGee investigate students' understandings of the relations between planes that are tangential to the graph of a real valued function of two variables, and the total differential of the same function. The paper presents an original combination of theoretical analyses of this subject matter: a genetic decomposition in the sense of Action-Process-Object-Schema theory (APOS: Dubinsky and McDonald 2001), and moments of study related to a reference praxeological model, in the sense of ATD. A main point is to relate the analysis of institutional organisations of subject matter and of study processes intended to engage students with this subject matter, to a cognitive analysis of students' actions in and recollections from these processes. As a result, the genetic decomposition is refined to include the notions of vertical change and the functional nature of the differential, along with a geometric interpretation of these notions. In turn, this refinement leads to the suggestion of necessary changes in the organisation of the study process.

\section{What Next?}

A measure of success for an initiative like INDRUM is legacy and longevity. As we are writing this editorial, INDRUM2018 is approaching (April 5-7, 2018; Kristiansand, Norway; chaired by Viviane Durand-Guerrier and Reinhard Hochmuth, with Simon Goodchild as Chair of the Organising Committee) and plans for INDRUM2020 are already under way. An ERME Topic Conference book is planned for publication after INDRUM2018. We envisage that this Special Issue alongside the INDRUM2016 Proceedings and the INDRUM2018 activities and Proceedings will inform the planning of this volume.

Certainly, research on UME is not restricted to the INDRUM community. On the contrary, regional and local initiatives, as well as more global forums for developing and sharing new knowledge on UME, are - and will continue to be - important for nourishing and complementing efforts in this setting (Nardi 2017). One particular characteristic of many INDRUM papers, certainly visible in the collection presented here, is the strong emphasis on theoretical precision, which needs to be enriched and strengthened through an ongoing dialogue with local practices. At the same time, settings like INDRUM are increasingly important to resource and validate investigations and interventions in local contexts, which are often constrained by policies and circumstances that should not be construed as "facts of nature" but as objects of research and potential areas for improvement.

We now invite you to carry on reading this Special Issue and we hope that the promise of its contents will encourage you to consider joining, or continuing to be part of, the ambitious and bold enterprise that is INDRUM!

Acknowledgements Before closing this editorial, we owe a big ThankYou to all the participants of INDRUM2016, whose contributions in Montpellier inspired and enabled the present collection, even if most will remain anonymous. A similar gratitude is due to the 57 scholars who participated in the anonymous, peer review of one or more papers for this special issue - in some cases for up to three rounds of revision! Finally, we thank IJRUME Editor Chris Rasmussen and the IJRUME staff at Springer for their sterling and prompt assistance at all stages of the preparation of this issue. 


\section{References}

Brousseau, G. (1997). Theory of didactical situations in mathematics. Dordrecht: Kluwer.

Chevallard, Y. (2018). Anthropological theory of the didactic. In S. Lerman (Ed.), Encyclopedia of mathematics education $\left(2^{\text {nd }}\right.$ ed.). Dordrecht: Springer.

Dubinsky, E., \& McDonald, M. A. (2001). APOS: A constructivist theory of learning in undergraduate mathematics education research. In D. Holton et al. (Eds.), The teaching and learning of mathematics at university level: An ICMI study (pp. 273-280). Dordrechet: Kluwer Academic Publishers.

Fischbein, E. (1987). Intuition in science and mathematics: An educational approach. Dordrecht: Reidel.

Gueudet, G., \& Trouche, L. (2009). Towards new documentation systems for mathematics teachers? Educational Studies in Mathematics, 71, 199-218.

Klein, F. (1908/2016). Elementary mathematics from a higher standpoint. Volume I: Arithmetic, algebra, analysis (translated by G.Schubring). Berlin: Springer.

Morrissette, J. (2011). Vers un cadre d'analyse interactionniste des pratiques professionnelles. Recherches Qualitatives, 30(1), 10-32.

Nardi, E. (2017). From advanced mathematical thinking to university mathematics education: A story of emancipation and enrichment. In T. Dooley \& G. Gueudet (Eds.), Proceedings of the tenth congress of the European Society for Research in mathematics education (pp. 9-30). Dublin: DCU Institute of Education \& ERME.

Nardi, E., Winsløw, C., \& Hausberger, T. (Eds.). (2016). Proceedings of the first conference of the international network for didactical research on university mathematics. Montpellier: University of Montpellier and INDRUM.

Sfard, A. (2008). Thinking as communicating: Human development, the growth of discourses, and mathematizing. Cambridge: Cambridge University Press.

Vandebrouck, F. (2011). Perspectives et domaines de travail pour l'étude des fonctions. Annales de Didactiques et des Sciences Cognitives, 16, 149-185.

Verret, M. (1975). Le temps des études I. Paris: Librairie Honoré Champion.

Winsløw, C. (2015). Mathematics at university: The anthropological approach. In S. J. Cho (Ed.), Selected regular lectures from the 12th international congress on mathematical education (pp. 859-875). Switzerland: Springer.

Winsløw, C., Gueudet, G., Hochmut, R., \& Nardi, E. (2018). Research on university mathematics education. In T. Dreyfus, M. Artigue, D. Potari, S. Prediger, \& K. Ruthven (Eds.), Developing research in mathematics education - twenty years of communication, cooperation and collaboration in Europe (Vol. 1). Oxon: Routledge. New Perspectives on Research in Mathematics Education series. 